Supporting Information

\title{
Does Spinel Serve as a Rigid Framework for Oxygen Redox?
}

\author{
Xiang-Mei Shi, ${ }^{\dagger}$ Eriko Watanabe, ${ }^{\dagger}$ Masashi Okubo, ${ }^{\dagger}, \dot{\dagger}$ Atsuo Yamada ${ }^{*}, \dagger$ \\ ${ }^{\dagger}$ Department of Chemical System Engineering, School of Engineering, The University of \\ Tokyo, Hongo 7-3-1, Bunkyo-ku, Tokyo 113-8656, Japan \\ \#Elements Strategy Initiative for Catalysts \& Batteries (ESICB), Kyoto University, Nishikyo- \\ ku, Kyoto 615-8245, Japan
}

*Correspondence to: yamada@ chemsys.t.u-tokyo.ac.jp 


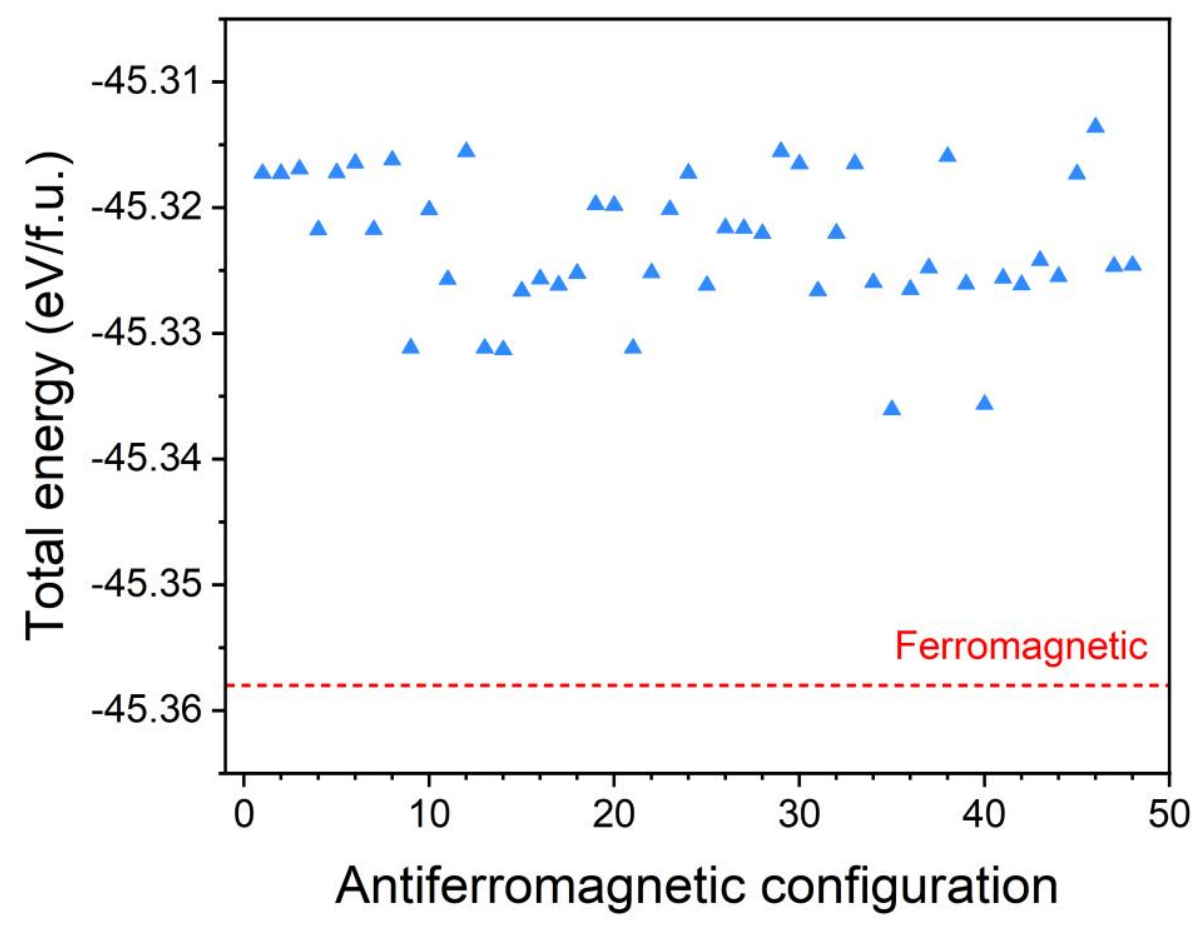

Figure S1. Total energies of $\mathrm{LiMg}_{0.5} \mathrm{Mn}_{1.5} \mathrm{O}_{4}$ in terms of 48 different antiferromagnetic configurations. The red dotted line indicates the total energy of the ferromagnetic configuration. There results were generated by $\mathrm{DFT}+U$ calculations. 
(a)

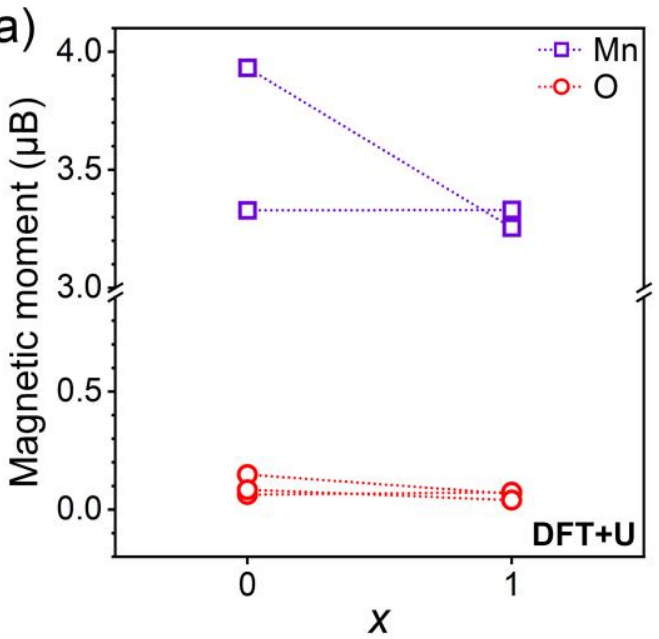

(c)

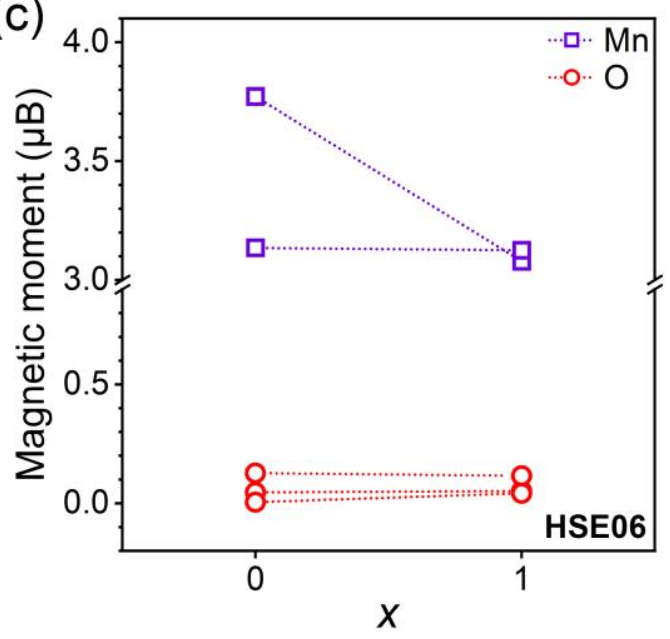

(b)

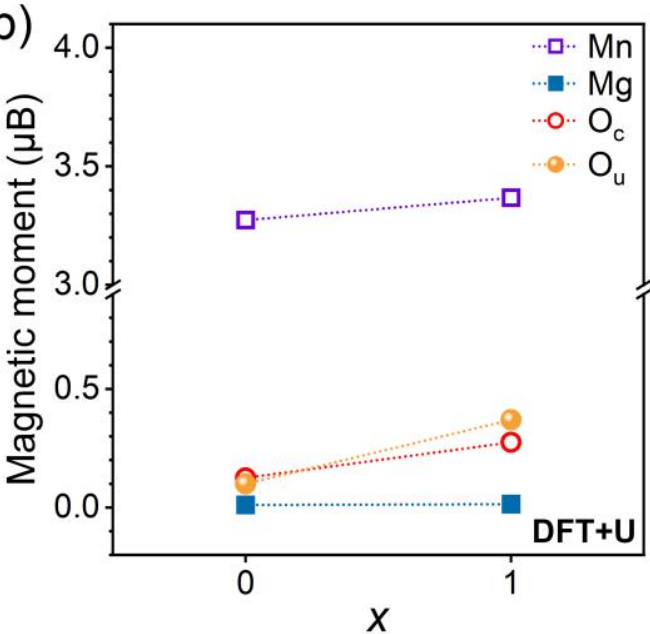

(d)

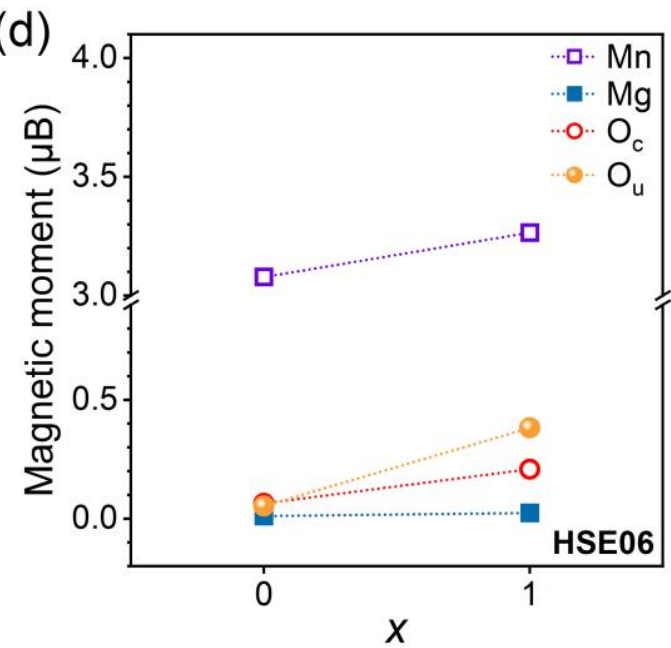

Figure S2. Calculated magnetic moments of $\mathrm{Mn}$ and $\mathrm{O}$ for $(\mathrm{a}, \mathrm{c}) \mathrm{Li}_{1-x} \mathrm{Mn}_{2} \mathrm{O}_{4}$ and (b, d) $\mathrm{Li}_{1-}$ ${ }_{x} \mathrm{Mg}_{0.5} \mathrm{Mn}_{1.5} \mathrm{O}_{4}$ with using $\mathrm{DFT}+U$ and HSE06, respectively. The conventional oxide ion coordinated by three $\mathrm{Mn}$ in $\mathrm{Li}_{1-x} \mathrm{Mg}_{0.5} \mathrm{Mn}_{1.5} \mathrm{O}_{4}$ is denoted as $\mathrm{O}_{\mathrm{c}}$. 
(a)

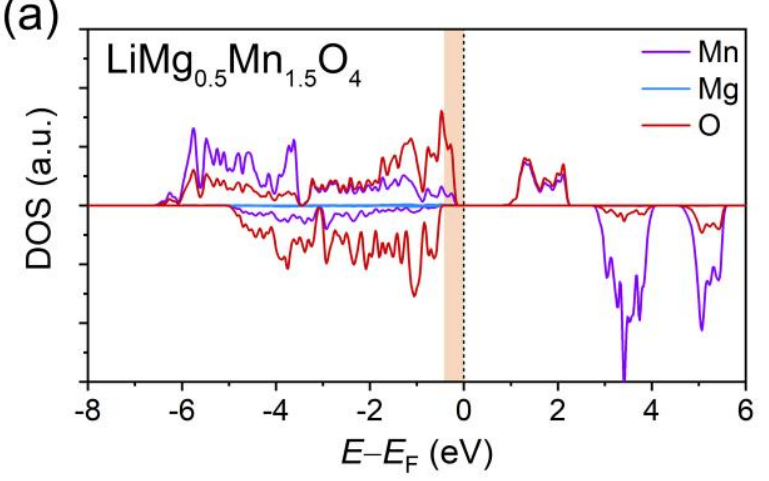

(c)

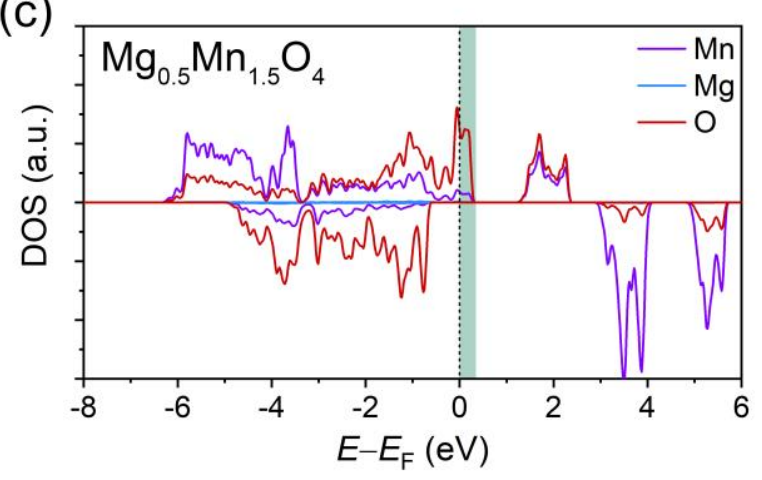

(b)

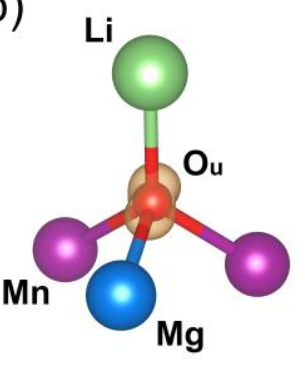

Electron density

(d)

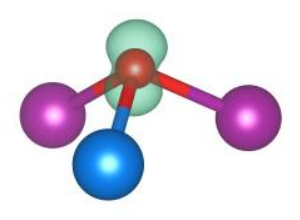

Hole density

Figure S3. DFT $+U$ calculations of DOS and partial charge densities for (a-b) $\mathrm{LiMg}_{0.5} \mathrm{Mn}_{1.5} \mathrm{O}_{4}$ and (c-d) $\mathrm{Mg}_{0.5} \mathrm{Mn}_{1.5} \mathrm{O}_{4}$, respectively. 
(a)

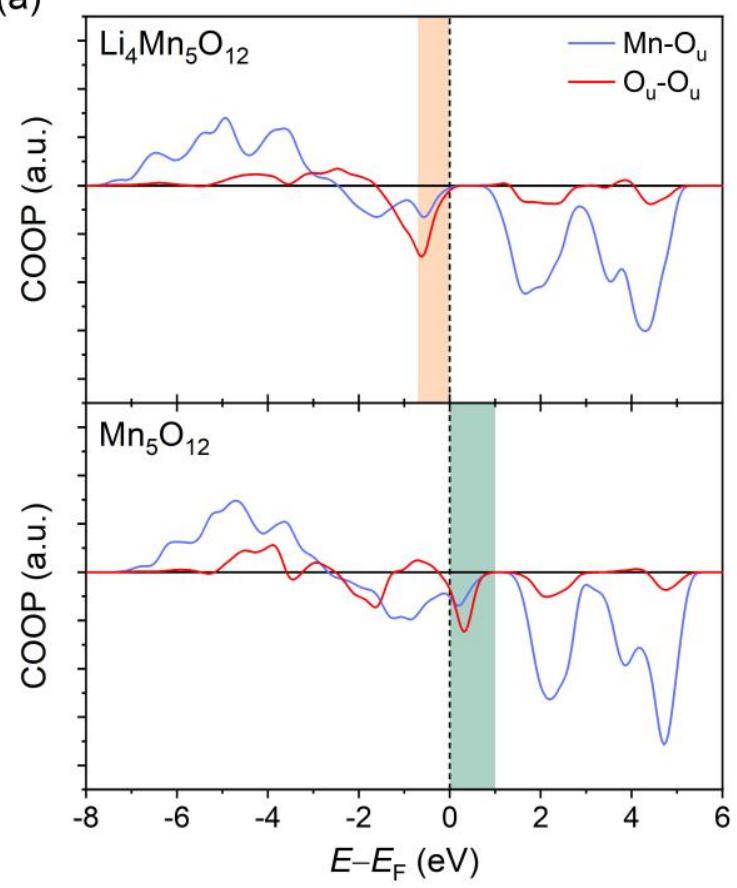

(b)

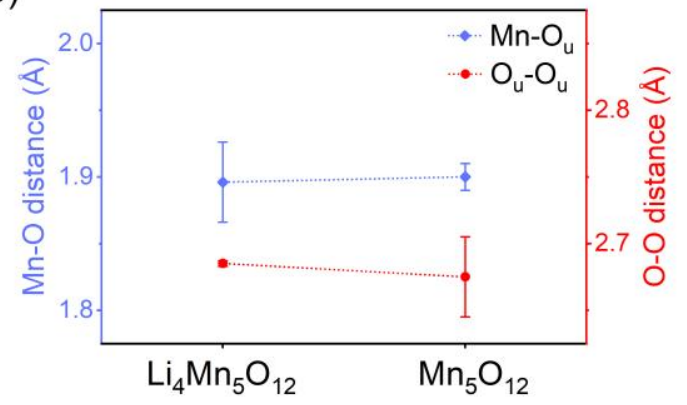

(c)

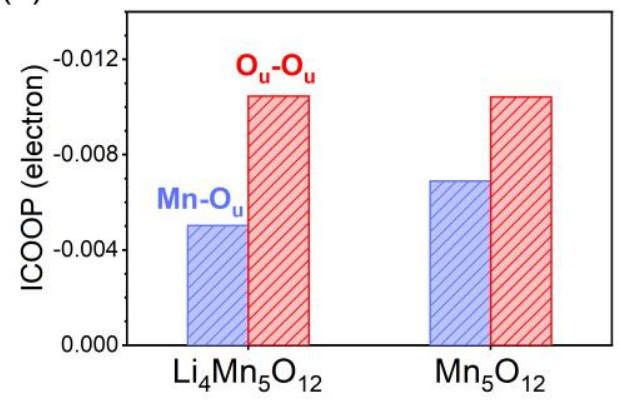

Figure S4. (a) Calculated $\left(\mathrm{DFT}+U\right.$ ) COOPs for $\mathrm{Li}_{4} \mathrm{Mn}_{5} \mathrm{O}_{12}$ and $\mathrm{Mn}_{5} \mathrm{O}_{12}$. (b) Interatomic distances for Mn-O and O-O interactions in $\mathrm{Li}_{4} \mathrm{Mn}_{5} \mathrm{O}_{12}$ and $\mathrm{Mn}_{5} \mathrm{O}_{12}$. (c) ICOOPs calculated within the shaded energy windows in (a). 


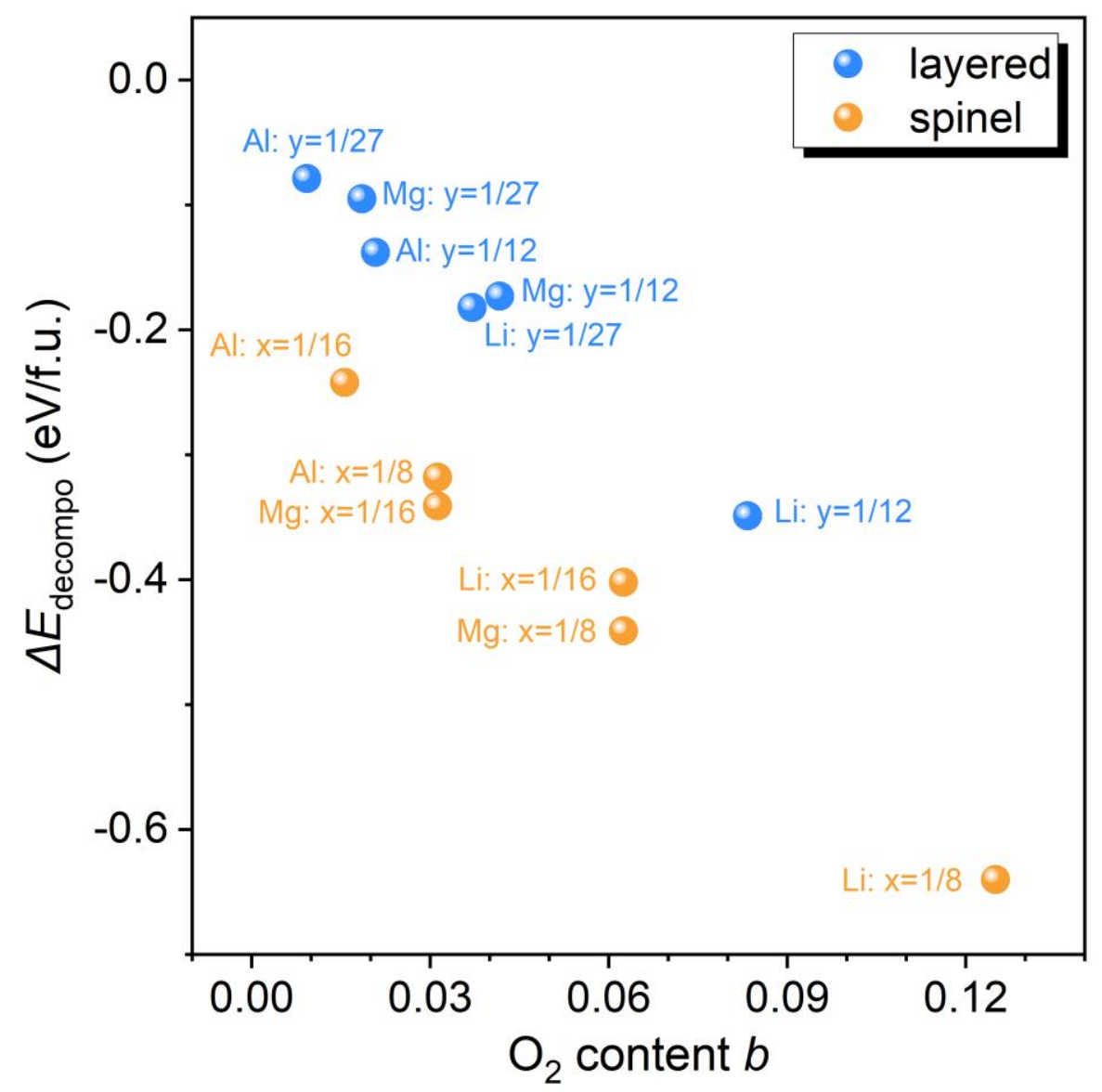

Figure S5. Calculated $(D F T+U) E_{\text {decompo }}$ of spinel $\mathrm{Li}_{0} \mathrm{M}_{x} \mathrm{Mn}_{2-x} \mathrm{O}_{4}$ and layered $\mathrm{Li}_{0} \mathrm{M}_{y} \mathrm{Mn}_{1-y} \mathrm{O}_{2}$, where $\mathrm{M}$ is $\mathrm{Li}, \mathrm{Mg}$, and $\mathrm{Al}$ respectively. The content of product term $\mathrm{O}_{2}$ in the decomposition reaction is defined as $b$. 